\title{
The I.P. Alimarin Prize
}

DOI: $10.1134 / \mathrm{S} 1061934811060177$

The I.P. Alimarin Prize for young scientists, which is awarded every year by the Division of Analytical Chemistry of Moscow State University, was awarded in 2010 to graduate student Aleksandra Fedorovna Prophorova for her works in capillary electrophoresis.

After graduating from the department of Chemistry of Moscow State University in 2007 with distinction, Prokhorova enrolled in graduate courses and since 2004 has been conducting research into the separation of enantiomers by capillary electrophoresis and HPLC and the determination of enantiomers of biologically active compounds in objects of various origin. She has prepared a candidate's dissertation on the use of macrocyclic modifiers of background electrolytes in capillary electrophoresis. She proposed adding macrocyclic antibiotic eremomycin and lignins to the background electrolyte for the highly selective separation of acid and neutral compounds. It was shown that eremomycin is superior to the known antibiotics, for example, vancomycin, in the enantioselectivity of the separation. Prokhorova has demonstrated the possibility of separating a series of profens, phenylpropionic acid derivatives, warfarin, coumachlor, etc. The proposed methods for modification of the surface of fused silica capillaries allowed her to reduce the adsorption of the chiral selector and achieve rapid (for no more than
10-15 min) separation of enantiomers of organic acids; the necessary amount of the chiral selector was decreased 5-20 times. The addition of lignins to the background electrolyte considerably improved the efficiency, selectivity, and reproducibility of the separation results.

Prokhorova has published and submitted for publication seven papers and two reviews, also in international journals. She was two times (in 2004 and 2005) a finalist of the Mendeleev Competition of students in chemistry. Her presentation made at the International Conference of Students, Graduate Students, and Young Researchers "Lomonosov-2007" was awarded an honorary certificate. In 2008, at the 16th International Conference on Electroseparation Methods in Italy, Prokhorova made an oral presentation and, in 2010, she received a grant of HPLC Inc. Prokhorova was among the organizers of the Moscow City Olympiad in chemistry; as teaching practice, she tutored first-year students of the Department of Biology and is tutoring fourth- and fifth-year students of the Department of Chemistry specializing in analytical chemistry. She was a cosupervisor of eight term papers on analytical and physical chemistry and two diploma dissertations. 